\title{
György Inzelt, Conducting polymers. A new era in electrochemistry
}

\author{
Series: Monographs in Electrochemistry, Editor: Fritz Scholz, 2008, XII, 282 p, \\ ISBN: 978-3-540-75929-4, 139.05 €
}

\section{Carita Kvarnström}

Received: 24 April 2009/Accepted: 24 April 2009/Published online: 12 May 2009

(C) Springer-Verlag 2009

Conjugated, electronically conducting polymers, their preparation, characterization, and the many new applications they have resulted in has led to the formation of a new field and society in organic electrochemistry. This field of conducting polymers has become very cross scientific where the solid-state physics, organic chemistry, and physical chemistry always have been present and interacting. The main objective of the monograph is to give an insight in the field of the electrochemistry of conjugated polymers both from an experimental and a theoretical point of view.

In Chapter 2, the synthesis and, in some cases, the mechanistic routes for different types of conducting polymers or electrochemically active polymers are described. The polymers have been classified in this chapter according to their mode of charge propagation. Mainly two main categories are discussed, the ionconducting polymers and the electron-conducting polymers of which the latter is more thoroughly described. Later in the book, Chapter 4 is completely devoted to the chemical and electrochemical synthesis of conducting polymers. The references are, for in particular Chapter 2, wide ranging and cover historically important developments up to 2007. Chapter 3 discusses different methods of investigating conducting polymers. Here, the challenge for the author was to present relevant and current examples representative for the huge number of published papers in this field. Nevertheless, the chapter represents in addition to the traditional electrochemical techniques also an overview of the most used techniques applied with electrochemistry in situ. For newcomers in the conducting polymer field and graduate students, the most informative and useful part of this book comprise Chapters 5 and 6. In Chapter 5, the author considers the thermodynamics for both a neutral and a charged polymer film. The 6th chapter is one of the most concise in the book dealing with the central issue of conducting polymers, namely transport processes or electron and ion transfer.

The main applications of conducting polymers ranging from antistatic coatings to artificial muscles are presented in a compressed form in Chapter 7. The applications were taken from publications heading back to the 1980s; this gives, on one hand, a good overview of the applied research performed during the last decades, but on the other hand, a summary of more recent publications would have given a better presentation of the state of art in the field.

An interesting addition is the 8th chapter dealing with some references to the historical background of conducting polymers leading back to the beginning of the nineteenth century.

Overall, this book could easily find use as a comprehensive reference guide for those interested in this field.
C. Kvarnström $(\bowtie)$

Laboratory of Materials Chemistry and Chemical Analysis,

Department of Chemistry, University of Turku,

Vateselankatu 2,

20014 Turku, Finland

e-mail: carita.kvarnstrom@utu.fi 